\title{
Mothering after Moomba: \\ Labelling, secondary stigma and maternal efficacy in the post-settlement context
}

\author{
Sara Maher, Monash University \\ Jarrett Blaustein, Monash University* \\ Kathryn Benier, Monash University \\ Joseph Chitambo, Monash University \\ Diana Johns, University of Melbourne \\ *Jarrett Blaustein, Tel. +61 0405512003, Email: Jarrett.Blaustein@Monash.Edu \\ 9,906 words (including references, footnotes, abstract etc.)
}

\begin{abstract}
Parenting can impact young people’s justice system involvement but there is a scarcity of research that examines how parenting practices, specifically mothering, are influenced by labelling processes. Accordingly, this article considers how the labelling of young people from forced migration backgrounds as criminals impacted mothering and maternal efficacy during a 'law and order crisis' in Melbourne, Australia. Drawing on interviews and focus groups with mothers and young people of South Sudanese heritage, we illustrate how this hostile social climate generated secondary stigma, and amplified anxieties and concerns about inclusivity and belonging. The research advances our theoretical understanding of parental control and parental efficacy in the post-settlement context by bringing the gendered experiences of mothers as providers of supervision and support into focus. It suggests labelling may undermine maternal efficacy and exacerbate intercultural and intergenerational tensions, but that community involvement may support parents and mitigate the risk of deviance amplification.
\end{abstract}

\section{Key words}

Maternal efficacy, parental efficacy, labelling, secondary stigma, post-settlement, forced migration, South Sudanese community, deviance amplification 


\section{Introduction}

Following the 2016 Moomba 'riot' ${ }^{1}$, media commentators and politicians repeatedly called attention to criminal incidents supporting the claim that Melbourne, Australia had a South Sudanese crime problem. The framing of this problem, described by some scholars, journalists, and human rights advocates as a 'moral panic', associated racial characteristics of young South Sudanese Australians with 'gangs' (Gaffey 2019; Majavu 2020). The 'gangs' narrative persisted for thirty-two months preceding the November 2018 Victorian State Election and had significant adverse impacts on young Australians of South Sudanese heritage who experienced stigmatisation, heightened racism, discrimination and surveillance (Macaulay \& Deppeler 2020).

From a criminological standpoint, the social and political construction of this crisis is unsurprising. 'Moral panics' and 'law and order elections' have become commonplace in Anglophone democracies and the criminalisation of migrants is widely documented (Weber 2019; Bowling \&Westenra 2018; Walsh 2018). Scholars have long acknowledged that young migrants of colour represent ideal 'folk devils' for opportunistic political elites and struggling media organisations (Hall et al. 1978; Welch 2012). The nature and dynamics of criminalisation processes, their systemic and structural causes, and impacts are widely researched. Surprisingly little has been written about the indirect parental and familial consequences of these processes, particularly for mothers from refugee backgrounds who must overcome barriers to education and employment, trauma, inappropriate government resettlement policies, and racism and xenophobia (Fozdar \& Torezani 2008; Tsai, Barr \& Welch 2017; Hayes 2013).

\footnotetext{
${ }^{1}$ This involved a public brawl at the 2016 Moomba Festival. We question whether the incident was actually a riot.
} 
This article examines how Victoria's law and order crisis amplified barriers that mothers and their communities faced for the purpose of theorising how the secondary impacts of criminalisation and stigmatisation impact parenting and maternal efficacy in the postsettlement context. Empirical insight is provided via interviews with mothers and focus groups with young people from the South Sudanese community in Melbourne conducted at the peak of the crisis. Our analysis highlights the disruptive indirect consequences of labelling on maternal efficacy during this panic, and how labelling and criminalization of young people, particularly those from forced migration backgrounds, may indirectly contribute to secondary stigma (Condry 2007) and exacerbate intergenerational tensions that further undermine mothers’ capacity to provide effective support and control. More optimistically, our analysis highlights potential strengths of non-Western parenting cultures that supplement maternal support and supervision via increased community involvement which may mitigate risks associated with offending and deviance amplification.

\section{Labelling and deviance amplification}

While subject to much debate, the labelling perspective remains influential in criminological research. The premise is that labelling individuals or groups 'deviant' may amplify offending behaviour if it causes stigma and 'spoiled' identity (Goffman 1963). This transformation of the self undermines existing social bonds (Sampson \& Laub 1993), increasing the likelihood of involvement with deviant peers and the frequency and severity of delinquent behaviour (Bernburg \& Krohn 2003). Over time, the concentrated effects of deviance amplification can also contribute to cumulative disadvantage (Sampson \& Laub 1997).

People may experience labelling effects regardless of their offending behaviour because deviance is a quality of societal reactions to individuals (or groups) rather than rule-breaking 
(Becker 1963). Individuals most susceptible to being labelled deviant typically come from marginalised backgrounds, with ethnic minorities and migrants particularly vulnerable due to factors including structural disadvantage, over-policing, criminalisation, and moral or political entrepreneurship that capitalises on culturally-entrenched racist and xenophobic discourse (Hall et al. 1978; Welch 2012; Sajjad 2018). Labelling effects are also often stronger for people from economically and socially deprived backgrounds (Adams, Johnson \& Evans 1998).

The criminogenic effects of labelling for young people are well-established but there is limited research that accounts for its secondary impacts on parents and parenting practices. Rather, the existing literature considers how parenting contributes to labelling processes and effects. For example, Matsueda (1992) found that parental appraisals of children’s deviance influence how children appraise their own identity, and parental attitudes and behaviours may therefore or exacerbate labelling. It is less clear how parents' perceptions of their children's behaviour are influenced by societal labelling processes, or how this might impact their parenting practices and perceptions of efficacy. Addressing this knowledge gap is important because family members of offenders, particularly women, are commonly 'drawn into shaming processes’ which contribute to ‘secondary stigma' (Condry 2007) or 'stigma by association’ (Goffman 1963). Secondary stigma can have debilitating consequences for mothers including self-blame, social isolation and in extreme cases at risk of victimisation (Condry 2007). The concept of secondary stigma thus provides a useful starting point for theorising how maternal attitudes and behaviours are influenced by their children being labelled ‘thugs' or ‘criminals', and how maternal responses may exacerbate or mitigate risk factors associated with deviance. 
Exploring these questions necessitates a review of the criminological literature on parenting and parental efficacy which is predominantly grounded in Western, specifically American, parenting norms, values, and experiences. By comparison, little has been written about the criminogenic or protective influences of non-Western parenting cultures and practices, particularly in post-settlement contexts, or how these are influenced by social problems such as racism, inequality, and social disadvantage. Thus, whilst we cannot ignore the 'orthodox' literature, nor should we assume that its findings, conceptualisations, and lessons automatically resonate with the distinct, complex, diverse experiences of parenting in culturally diverse communities, especially post-settlement contexts. Researchers must therefore adopt a critical stance and question ethnocentric assumptions of the established literature when studying the criminogenic or protective effects of practices and capabilities in non-Western or inter-cultural contexts.

It is also important to acknowledge that the 'orthodox' criminological literature on parenting and parental efficacy is overwhelmingly gender-blind and has little to say theoretically about the role of mothers and mothering. Rather, criminological research on mothering has typically been the domain of critical and feminist scholars who examine women’s experiences of primary (Seccombe, James \& Walters 1998) and secondary stigmatisation (Condry 2007), maternal activism in the aftermath of lethal violence (Cook 2020; Lawson 2018), and the criminalization and responsibilization of maternal conduct (Roberts 1995). Although these literatures do not explicitly engage with experiences of mothers in the postsettlement context, they highlight the benefits of examining the gendered scrutiny that mothers, particularly women of colour, experience in Western patriarchal societies.

\section{Parenting, parental efficacy and adolescent offending}


Parents provide support and indirect controls through parent-child attachments (Hagan 1989; Gottfredson and Hirschi 1990). They also influence children’s behaviours by monitoring activities and punishing undesirable conduct to deter future antisocial behaviour. Parenting behaviours may also influence youth justice-system involvement and research suggests young people's offending behaviour is inversely proportional to the support and warmth provided by their parents (Baumrind 1991). Authoritative parenting, characterised by appropriate balance between parental support and control, is argued to be least likely to result in offending, while uninvolved parenting approaches are most likely to result in anti-social behaviours (Baumrind 1991; Wright \& Cullen 2001). Uninvolved parenting is also associated with childhood depressive symptoms in a sample of African-American children, along with racial discrimination and criminal victimisation (Simons et al. 2002). Authoritative parenting styles are particularly effective at deterring offending in communities characterised by high collective efficacy (Simons et al. 2005). In disadvantaged neighbourhoods, nurturant and involved parenting together with collective socialisation are inversely associated with children's deviant peer affiliations, whereas harsh and inconsistent parenting are positively associated with this proxy for offending (Brody et al. 2001).

Wright and Cullen (2001) further inversely link young people’s delinquency to parental efficacy. This refers to a "parent's belief in his or her ability to influence the child and his or her environment to foster the child’s development and success” (Adelt \& Eccles 2001: 945). It can also refer to parents' belief in their ability to effectively parent (Smith 2017), or to positively influence the behaviour and development of their children (Coleman \& Karraker 1997; 2000). In Western societies, cohesive family structures with two biological parents are argued to enhance parental efficacy by providing parents with more resources for supervision compared to fractured family structures (Browning et al. 2008). Communities in which 
households are headed by a single parent are therefore associated with higher rates of youth offending behaviour. This has been attributed to the fact that two-parent households often have greater social capital at their disposal and the advantage of sharing the task of supervising and monitoring children compared with single parent households (Sampson 1986). These challenges and their impact on parental efficacy are important, but it is necessary to consider why they exist. To this effect, Dowd (1997) argues that the efficacy of single parents, particularly single mothers of colour in Western patriarchal societies that valorise the normative two-parent family structure, is undermined by social stigmatization, social disadvantage, and inadequate levels of economic and social support. As discussed in the following section and the wider literature on refugee mothering (Tsai, Barr \& Welch 2017; Hayes 2013), these factors are particularly acute in many post-settlement contexts.

Research on the effect of labelling on parental efficacy is scarce and little has been written about the impact of stigma and negative attention on parental attitudes and behaviours. Ali (2008) suggests that parents who migrate from poor countries to developed countries lose their sense of self-efficacy in their parenting role due to a sudden reduction in their social, emotional, cultural and financial resources. The interaction of migrant families with the social institutions of the countries in which they settle perpetuates their sense of inadequacy, inferiority and lack of personal efficacy. These cumulative disadvantages are further exacerbated by the expectations placed on migrant parents to conform to dominant Western models of family life, which may be unfamiliar or contradict traditional parenting practices. While this study does consider parental efficacy in a post-settlement context, it does not specifically examine the gendered experiences or contributions of mothers.

\section{Post-settlement parenting in the South Sudanese community in Australia}


The South Sudanese are the largest recently-arrived community of refugee background in Australia - the largest community of which resides in Melbourne. Far from homogenous, the community consists of multiple ethnic groups with distinct languages and cultural practices. Racism and discrimination remain major obstacles to South Sudanese settlement where there is a longstanding Australian history of discrimination against non-white migrants (Scanlon Foundation 2016; Losoncz 2017). Racism and discrimination were found to be the key cause of South Sudanese students dropping out of school (Baak 2018) and the community experiences an unemployment rate of 28.6\% compared to 5.7\% nationally (El-Gack and Yak 2016). Discrimination in the job market has been linked to family breakdown, intergenerational conflict and social isolation (Abur 2017) and blocked employment opportunities are experienced by community members as a sign of disrespect (Losoncz 2011).

Many South Sudanese families who migrated to Australia are headed by single mothers (Omitted 2). Raising children alone, without support of the traditional extended family, has posed unique challenges for these women during settlement and post-settlement (Hebbani, Obijiofor \& Bristed 2009; Levi 2014). Additional challenges are the cultural, linguistic and systemic barriers mothers faced in gaining an education in Australia (Hatoss \& Huijser 2010). Low literacy is the basis of long-term, welfare-dependent poverty, with significant consequences for women and their families' mental health and well-being (Omitted 2). These issues are compounded by government interventions related to the care of children, which are perceived as a threat to the cultural identity and traditions, and thought to undermine parental authority and family welfare (Losoncz 2011; Losoncz 2015; Levi 2014). 
Former refugee parents typically report tensions between the traditional expression of parenting and expectations of the settlement country (Deng and Marlowe 2013; Jaysane-Darr 2013; Levi 2014; Deng 2016; Salami et al. 2017). The collective social responsibility of raising a family through the extended family system is often weakened or absent in the host country. In Australia, single mothers have grappled with pressures of individual responsibility during the challenges of settlement (Dhanji 2010; Salami et al. 2017). In this vein, Renzaho et al. (2011) found parents from African migrant communities in Australia are particularly restrictive when their children sought degrees of independence not typical for children of an African family. The resultant parenting styles discouraged children's autonomy, emphasised hierarchical decision-making, and attempted to control children's social development and behaviour through strict boundary-setting, close monitoring of friends, activities and interests (Renzaho et al. 2011, p. 228). These findings are consistent with research that suggests that parenting practices of African migrants are typically more conservative than those of Western host countries (Salami et al.’s 2017). This is important because it highlights how intercultural tensions intersect with intergenerational tensions as children and parents are exposed to divergent value systems.

Changes in gender roles are also key concerns for South Sudanese Australian parents (Losoncz 2015; Deng 2016). While it is traditionally the mother's role to raise children, her focus is her daughters (Deng 2016). The father's responsibility is therefore to teach male children their roles and responsibilities in the family, clan and tribe, with uncles and older cousins also contributing (Deng 2016). If their children leave the family home, however, which in the Australian context boys are more prone to do - the father's authority is undermined (Kot 2018). Hebbani, Obijiofor and Bristed (2009) found that Sudanese mothers felt their children had abandoned their heritage for an Australian identity and in doing so, 
undermined a mother's authoritative role in their lives, and their ability to influence their social development. A distinct aspect of the migration and settlement process, therefore, is the challenge it poses to these traditional roles, particularly for single mother households (Kot 2018; Levi 2014). The challenges are further amplified by the need for refugee mothers to reconcile values and practices with 'an idealized model of motherhood, derived from the situation of the white...middle class, [which] has been projected as universal' (Glenn 1994: 3). Despite these documented challenges, Macaulay (2020) suggests that youth/parent relationships play an important role in shaping young people's transitions to adulthood within the South Sudanese community in Australia.

\section{Maternal efficacy in the post-settlement context}

We suggest that maternal efficacy provides a useful framework for considering the gendered impacts of labelling and stigma on mothers' perceptions of their ability to provide effective support and supervision in the post-settlement context. We have adapted this definition from the literature on 'parental efficacy' rather than the literature on 'maternal self-efficacy' because the latter is primarily concerned with mothers' perceived ability to provide post-natal care and support early childhood development (Coleman \& Karraker 2003). Linking maternal efficacy to the criminological literature on parental efficacy therefore affords us with greater scope to theorise mothering as an important, gendered aspect of parenting that shapes the development of young people beyond infanthood, and into adolescence and early adulthood. This is the time when young people are most likely to come into contact with the youth and criminal justice systems (Farrington et al. 2013), and experience stigma and deviance amplification (McAra \& McVie 2007). ${ }^{2}$ The gendered concept of maternal efficacy therefore

\footnotetext{
2 Young South Sudanese Australians were over-represented in the official statistics during Victoria's law and order crisis, albeit for complex reasons including the age demographics of
} 
allows us to analyse secondary stigmatisation experienced by mothers of young people from refugee backgrounds in this post-settlement context during a law and order crisis that amplified the challenges described in the previous section, and put young South Sudanese Australians and the wider community in the public and political spotlight.

\section{Methodology}

Our study set out to examine how intercultural parenting challenges were compounded by the law and order climate that emerged following the 2016 Moomba 'riot'. Data were collected during the 12 months preceding the 2018 Victorian State Elections, when narratives about South Sudanese gangs were in active circulation. Young South Sudanese Australians had previously been publicly labelled a problem group in Australia (Windle 2008) but in the two years preceding the 'riot' (2014 - 2015), there was minimal discussion of South Sudanese criminality in the media (Omitted).

We approached this research using focus groups with young people and interviews with mothers to capture the lived experiences of participants whose voices were overwhelmingly absent from the public debate about 'African gangs'. During the first phase, we recruited 28 focus group participants, aged 15 to 23, through our community-based partner, the Centre for Multicultural Youth. These were peer facilitated and focused on the impact on young people and their community of the media coverage since Moomba. Most participants were young women ( $\mathrm{n}=25)$ as we struggled to recruit a balanced sample that included young men who were more directly targeted by the media narratives. The young women were nevertheless affected by the post-Moomba climate and discussed how they and their male siblings

the population, cumulative disadvantage, and ongoing experiences of discrimination and over-policing (Shephard \& Spivak 2020; Weber 2019). 
experienced stigma and changes in parenting practices as a consequence. The focus groups were conducted in English as all the participants grew up in Australia. A preliminary analysis of young people’s experiences was published as [Omitted], so this article primarily focuses on the perspective of mothers and focus group data is used to expand upon key themes by adding a youth perspective.

In the second phase, we recruited mothers for semi-structured interviews that were conducted individually and in small groups between June and September of 2018. Only mothers were recruited and interviewed for this study on account of the significant number of single-mother households within the South Sudanese community and the sensitive nature of the research which necessitated the recruitment of participants via the lead author's long-established networks of South Sudanese women. The lack of direct empirical insight from fathers is a limitation and this has informed our decision to focus our analysis and theoretical discussion primarily on maternal efficacy and mothering as elements of parenting in this context.

The 17 mothers we interviewed had migrated to Australia between 1999 and 2006. Nine arrived as single mothers and seven with husbands and children, however two separated from their husbands after relocation. The women arrived with between two and eleven children and the average age of their sons at the time of the interviews was eighteen. The participants represented four ethnic groups (Kuku, Collo, Nuer and Dinka) and resided in eleven suburbs in the Western and South-Eastern regions of Greater Melbourne. Interviews were conducted in English, the use of which was canvassed prior to undertaking interviews (though some incidental translation occurred amongst the women and by family members). Participants were asked about the impact of the post-Moomba climate on their lives and communities, 
whether they perceived a 'youth crime problem', their relationships with their children, and if/how they had adapted their parenting practices in response to these circumstances.

\section{Secondary Stigma after Moomba}

Participants acknowledged post-settlement challenges but described their early years of settlement in Australia positively. Specifically, the women expressed appreciation of the education system, the safety and security their families enjoyed in Australia, and a sense of belonging. The Moomba 'riot' in 2016 was perceived as a distinct turning point in their postsettlement lives however because media portrayals of South Sudanese 'gangs' undermined this sense of belonging, added new dimensions of stress to community life, worry for the safety of their children, and prompted questions about their capabilities as mothers - with motherhood being the central identity of a married women's life (Mamer 2020). Women were subsequently conscious of being watched, fearful of reactions from members of the public, and more aware of being visibly different.

Now, when I go shopping centre here, now it's changed. Every time you go, before long, years ago, no one was been check on you, but now everybody look. When you see - when they see you, they shocked.... They say we are gang whether the woman or man or grandmother or grandfather, they are thinking that we are gangs. This word is killing us as a family. Our kid are not gang. African are not gang. What they're doing is what youth are doing in Australia. Other white kids now, they are doing terrible stuff, and no one say they are white gangs. No one's saying that. Chinese, they are doing wrong thing, and no one say they are Chinese gangs. Middle East, they are doing wrong thing, and no one say they are - because of their skin, of their skin, and I'm sorry, our skin is a victim in this country, and we cannot change 
our skin. We are proud of our skin and we are proud where we come from. (Mother 13)

Personal interactions with people exposed degrees of rudeness, coldness and, at times, obvious aggression that were new to their experience in Australia.

I used to say like Australia is a, um, please and thank you country, what's happened to that person? Like, why is he not saying thank you to me? And that's part of what's happened. Since the news, we're not like, um, been treated the way it should be, the way it used to be back then. There's a difference, a lot more differences, yeah.

(Mother 6)

The perception that the community was indiscriminately targeted by media, politicians and other sources also contributed to the loss of trust amongst mothers. They perceived it as unfair and frustrating, especially the way their entire community had been depicted as responsible for the behaviour of a few.

... people are getting worried because they are saying African gangs, South Sudanese are - or any youth is assumed to be a gang... Why don't...the authority people just focus on those people who are the problem causers - and then let them face the consequences?....don't name the whole community or the whole youth group from that community to be gangs. (Mother 2) 
...we always feel, feel the stigma because when you go outside, people look at you, what your child did outside or even [if] it's not your child. "The African, the, they did it” or we're all African and you feel the shame all the time. (Mother 1)

These narratives illustrate that mothers, both as parents and community members, were indirectly affected by the law and order crisis, and the subsequent labelling process. They experienced secondary stigma as a consequence of childrens’ perceived deviance. All mothers in our study reportedly experienced this stigma after Moomba yet only two of them had children who might be regarded as 'serious offenders'. From a theoretical standpoint, this is important because it suggests that in the post-settlement context (and presumably other contexts where structural relations to a stigmatized individual are defined by race or migration status), secondary stigma is not limited to family members of serious offenders but also of those young people who are indiscriminately labelled problematic. This is consistent with the wider sociological literature on courtesy stigma (Goffman 1963) which establishes that deviance is defined in relation to characteristics of the actor as opposed to their actions (Becker 1963). It is also supported by research which indicates that prejudice is an important element of stigma (Rusch, Angermeyer and Corrigan 2005), and the racialised and xenophobic 'gangs' narrative which received widespread coverage in the media (Majavu 2020) was particularly harmful in this respect.

\section{Anxieties, strain and parental efficacy}

Secondary stigma experienced during this law and order crisis was clearly distressing and a source of anxiety for mothers. Cultural mixing amongst young people had previously been a source of concern of mothers (Omitted 2) and these concerns were amplified by the law and 
order climate and the media coverage of Melbourne's 'gang' problem which generated new anxieties about the safety of children and behaviour that may lead to contact with police:

I think the community has been worried, particularly people with the children. They've been worried on what's going on. You could hear mothers saying that - oh, if they shouldn't go out and they don't come back, they're just worried, you know, “What's gonna happen? I don't know what's happening to them, whether they're safe or not," that kind of worry. (Mother 2)

Mothers dismissed the idea that 'gangs' were a problem in the South Sudanese community and most of them described their children as 'good'. Nevertheless, the interviews highlighted several potential risk factors for offending-involvement and some mothers were concerned about their children's behaviour as teenagers and their transition to adulthood. Risk factors identified by mothers included: negative peer influences (mainly with young people from other ethnic and cultural backgrounds); drug and alcohol use; agency intervention in family life; and barriers to education and employment, which mothers recognised to be a significant source of strain for their young people.

There's a lot of people now, they have, you know, qualification but they don't find jobs because sometime they might be like - they're looking for us to be receptionist or it just very simple jobs. And because of, you know, maybe the colour - the colour of the skin, they will not - "Oh, we're gonna call you.” And not - and they - they - they never get a job, because, you know? Maybe they will think about, "Oh, is this person gonna be a receptionist is gonna chase away all the customers," you know what I mean? So, we try and learn how to have a conversation with our kids to say, "Look, 
we've been here, we're trying our best to - try your best to do what you can. It - I know it's hard, but try your best," because I don't even know what's future gonna hold for our kids. (Mother 6)

While the issue of blocked employment opportunities was not new (Shepherd, Newton and Farquharson 2017), young focus group participants felt this problem had been amplified by media portrayals of South Sudanese criminality.

Well, our communities, people within our communities are unable to get the jobs they want. Obviously, it's been an issue, like, before this situation happened but now it's become worse. So. That's a big problem within our community. Cuz they are being seen as criminals again and untrustworthy people. (Participant 4, Focus Group 1)

Blocked opportunities thus represented a significant source of frustration and stress for young people whose conservative parents expected them 'to grow up to be very independent, to be very responsible, to have a good career or educational background and career' (Mother 2).

Mothers understood these barriers and expressed concern about how these frustrations were impacting young people’s social development and behaviour.

Some of them are frustrated because they couldn't get jobs. They struggle and then, what do they do? They end up just loitering around or finding themselves idle, and they end up doing such kind of - it encourages them to do such a kind of behaviours, or drinking. And then, when you're drunk, what does it mean? You start doing other things, which you didn't plan to do. Obviously, later on, you regret, but - yeah. But if 
the possibility of really getting jobs and they're kept busy, I think they will not have time to be messing around, trying to do such kind of things. (Mother 2)

Some of the mothers we interviewed lacked the educational background, cultural knowledge and social capital required to help their children overcome these challenges. Accordingly, their parental interventions emphasised promoting responsible behaviour and increasing supervision and support for their children. These strategies were oriented towards preventing 'good' children from making bad decisions that could jeopardise their futures. Mothers seemingly accepted that misbehaving was normal for adolescents in Australia, but understood that the risks and consequences were greater for South Sudanese teenagers due to their visibility, and the heightened scrutiny and surveillance that they faced, especially after Moomba. Getting into trouble was therefore a social privilege that young people from the South Sudanese community were not afforded. From a cultural standpoint, mothers also perceived anti-social/offending behaviour as antithetical to traditional South Sudanese values, and a source of shame and stigma, not only for the community, but for themselves as mothers.

\section{Promoting responsible behaviour}

Mothers saw it as their parental role to emphasise and promote the responsible behaviour traditionally expected of their children. This is consistent with the family values of the South Sudanese and other African communities (Salami et al. 2017) and multiple participants described how they continuously told their teenagers to make responsible decisions and stay out of trouble. Much of this advice was oriented towards encouraging young people to respect parental and institutional authority. 
This is a good country. If you listen, you will be good for right way. If you're not listen, you will get trouble. The same thing if you are at home. If you not listen, you will get trouble. (Mother 7)

The emphasis on respecting authority, both at home and in other settings, was linked to mothers' aforementioned concern that children's exposure to Australian culture was eroding the role of elders and parents in the traditional authority structures within the South Sudanese diaspora community.

Mixing culture is the hardest. They're confused. So the mix in culture is a big key of hard life for our kids because what our kid hear from us, not what they hear from Australia. Let's say when your child starts school - in my culture, you don't sit and talk to your mother like this or your father or one of your aunties. You have to face your eyes down. You don't need to look in their faces. When your mother call you, you come and you say, "Yes, mum?” This country, you call your child, "What? What do you want from me?" It shock us. So the main key is the culture. (Mother 13)

They will live me with my culture. They will go. What they do, what they do, children are doing out, I don't know, but when my children see it, they will do it. That is why I say we fight over the two cultures. That they will bring, what? They will bring thing like what happen now. We don't have a big thing to do it because two cultures - we can't manage it. (Mother 7)

For mothers, this perceived erosion of South Sudanese culture was experienced as a breakdown of their traditional gendered role, undermining their ability to contribute to the 
maintenance of family and community life, and diminishing their maternal efficacy when it came to guiding young people during their transition from childhood to adulthood.

Young people's exposure to Australian values was also perceived to be criminogenic because it encouraged a degree of autonomy that undermined traditional South Sudanese parenting approaches and relationships.

..in our culture, children don't, don't fight with big people or they don't disobey big people, in our culture, and that's why you see they are not involved in crime because they, they don't, they don't disobey big people, if they saw a big man, sometimes, they escape and hide somewhere there because they don't want to answer, to respond to. It is part of the culture. Then, the other thing is that that is not part of our culture, never, you can't hear a Collo man stealing, in the culture, the real culture. (Mother 10)

This mother's sentiments are consistent with earlier research by Hebbani, Obijiofor and Bristed (2009). Heightened anxieties about young people's behaviour during this law and order crisis thus seemed to validate longstanding concerns that autonomy and exposure to Australian values was criminogenic.

Some mothers' anxieties about youth autonomy and diminished sense of maternal efficacy were further exacerbated by previously documented frustrations about their inability to discipline children using traditional methods in Australia, including corporal punishment (Hebbani, Obijiofor and Bristed 2009). Australia’s emphasis on ‘children’s rights’ was 
therefore described as an obstacle to the ability of parents to discipline their children and promote responsible behaviour.

What I see is a wrong thing in whole Australia is something called 'child right'. We don't have that. What is called 'child right'? That is one thing is difficult in this country. (Mother 13)

I can't follow them with my culture and I can't, I, I can't leave her with the Australia culture. If I say, I can't leave her with the Australia culture, I'm going to jail myself. The child will take me to jail because if I say, "No, don't go to out.” They will call for Child Protection, police, they will say, I treated, I treated wrong. I have to go to jail. We don't know what can we do? (Mother 7)

Confronted by the criminogenic influences of Australian culture, enduring concerns about state interventions, and having to limit their use of traditional South Sudanese parenting methods, mothers became self-conscious; concerned that they were being perceived as ineffective mothers, within their own community and outside of it. Given the significant cultural emphasis attached to mothering in South Sudanese culture, a woman's perceptions that she might be failing in the role would have likely have a significant impact on her maternal efficacy.

\section{Increasing supervision and support}

Mothers responded to diminished maternal efficacy by attempting to increase supervision and control to reduce the risk that adolescents might find themselves in bad situations, interacting with negative peer influences, making poor decisions, and ultimately coming into contact 
with the law. This strategy also involved attempts to educate their children about the risks they faced and the hostile climate. As one mother explained:

Yeah. I speak to them. Teenagers are teenagers, especially. I try to explain to them what is happening, outside there's a lot of trouble, and try to encourage them to come home early, not to stay out late or to avoid going to places where there are a lot of maybe like pubs or something. (Mother 2)

The notion that parental supervision increased in the aftermath of Moomba is also supported by focus group data. As one young person explained.

It woke up, like, our parents as well. 'Cos, I feel like, before the whole incident happened, kids were basically lying to their parents and saying, 'Oh, we're going to the movies with my friends,' or 'I'm going here, I'm going there.' So, parents had no idea what their kids were getting up to in the outside world. Um, and for the media it's kind of like, now our parents are more cautious of what their kids are doing and who they're hanging with, and what time they [stay] out [until]. 'Cos now they're worried, um, 'cos their child might get in trouble next. ... Parents are always, like, trying to track down kids and, um, be extra careful of who they hang with, and where, especially, like, what areas they hang in. ... But at the same time, like, um, even though parents are more aware now, it's kind of like, for the younger kids, it's like, now there's no more trust. And now they're being labelled as this, so now they are, like, our parents, or their parents now think, 'Okay, since you're always out, oh you're doing this. So, you, this is what, this is what you were getting up to.' So, not it's like ... it's created, like, a little issue within our own community. 
(Young Person 1, Focus Group 2; also quoted in Omitted)

Considering the gendered nature of parenting is important in this context because focus group participants suggested fathers were stricter than mothers when it came to limiting social activities. Our inability to compare the perceptions of mothers and fathers is a limitation of the study however, our interview data suggests that mothers did not generally perceive their children as troublemakers but instead recognised their vulnerability. For example, some mothers were concerned about purported attempts by organised criminal groups to recruit disaffected young South Sudanese men to commit offences on their behalf. As one mother explained.

...they [the media] say that those South Sudanese are being led by certain people who can use them, and that means, if a child is not in relation with their parent, can be used by anybody else around in the street... (Mother 10)

Another aspect of their perceived vulnerability related to racist bullying, and specifically the risk that this could provoke a violent reaction. Multiple focus group participants reported either personally experiencing or witnessing bullying and racial abuse (Omitted). Mothers understood that young people were particularly vulnerable to bullying in the post-Moomba climate due to the stigma associated with the 'gangs' narrative and some actively discouraged their children from socialising in public with groups of friends.

Mother 3: Stay by himself. It's better for your life. If you put yourself in the group, you'll get in trouble because there is some people, they walk together and then will or drive something, you never know, but something up in front of you, you'll be in shock 
the last minute, because you don't before if you put yourself in the group. Stay away. Keep yourself as a different person should be okay. "This word I give to you because I wanted to defend your life."

Interviewer: And when you say that to him, does he agree or not?

Mother 3: Yeah, agree, he said, "Yes mum, I agree for this."

Interviewer: So, he stays away from a group?

Mother 3: Yeah. He says, 'I don't want that'. I know my son. 'I don't want to do this'.

From an intercultural standpoint, this is important because publicly socialising in groups is an important social and cultural practice for young people in African communities. Unfortunately, as one focus group participant explained, this cultural practice was misunderstood in Australia and put young people at greater risk of coming into contact with police.

Like, I'm not trying to sound rude in any way, they [Australians] never really had a culture where people are together as a group, you know, like, back home you see people in a group. You never see a sister or a brother walking alone. It's always with a group. You know what I mean? And to them, it's something new. So, instead of having to invest time and seeing it in a positive way, they choose to see it in a negative way. (Young Person 3, Focus Group 3; also quoted in Omitted)

Not all the mothers discouraged their children from hanging out in groups, however, and some even advocated it as a safety strategy, even though they recognised it could attract negative attention. 
The mothers overwhelmingly believed that their children were safer at home but also acknowledged that their ability to monitor their children 'inside' was limited due to their technology use.

You worry a lot. We worry a lot. Because even you sit inside the house with the kid, maybe you don't know [they] do something outside; inside the room [on phones or computers] or outside. You're very worry. You very worry a lot, yeah, and not happy. Now the parent very stressing. Yeah, we need help. (Mother 15)

The challenge of monitoring young people's use of technology is by no means unique to the South Sudanese community yet these mothers' challenges with digital literacy were seemingly compounded by the educational and linguistic barriers that they faced (Omitted 2). This represented an additional source of concern for mothers which seemingly heightened their diminished sense of efficacy.

Young people acknowledged their parents' anxieties, but many felt that attempts to increase supervision and restrict opportunities for socialising were disproportionate to the actual risks they faced. They perceived these restrictions as unfair because they limited their ability to fully participate in Australian society and enjoy the same freedoms as their peers from outside the South Sudanese community. Some participants expressed frustration at what they perceived to be an indiscriminate parental response to the media's coverage of 'African gangs'. They interpreted this as a lack of trust from their parents because 'It's created, like, more conflict, between, like, the older generation and the younger generation. Which shouldn't be the issue' (Young person 3, Focus Group 2; also quoted in Omitted). 
While the perception that parents did not trust their children to act responsibly was evident from our focus group data, young participants were overwhelmingly appreciative of their parents' efforts to provide them with a better life. They did not necessarily agree with their parenting methods, or subscribe to their conservative values, but nevertheless recognised their attempts to be supportive and valued their attachments to both family and the South Sudanese community (Omitted; also Macaulay 2020). The idea that effective parenting necessitates a balance between authority and support (Baumrind 1991) thus resonated with the values and practices of the mothers we interviewed and was evident from their attempts to protect their children from the post-Moomba climate. As one mother explained:

I have to tell them "Look, if you going somewhere, I am available for you. Talk to me anyway, any time you want. Call me if you need help. I am here for you. My phone is here. Call me if you in trouble or you need help.” (Mother 14)

\section{"We talk as a community and we're talking together."}

Increased support was also provided by other family and community members who aided both mothers and their children. Community networks including elders have also played an important role in supporting single mothers and young people during resettlement (Deng and Marlowe 2013). This was particularly evident in the aftermath of Moomba when community concerns about young people and reputational damage were at their peak. As one participant explained.

[My nephew], he'll go and play and he will come with his friends and the fact that we are scared of our kids walking around outside there; we always call him like, "Are you okay? When are you coming?” you know? Because his mother and I, we get 
concerned, you see? Because the police everywhere and the station and they all look at you; you're just walking around in the middle of 8 PM or 7:30 PM, they will, like, ask you where you're going, where are you coming, you know, in a rude way, you know? And some kids they are like, “Look, I'm walking. I'm minding my business. Like, Why? What did I do? I'm not holding anything bad, like just leave me alone," you see? So, we always get worried when our kids are outside there playing basketball and they're gonna come home, so, sometimes we pick them up because we don't want them to involve with any police question, because they will get angry. And they will be like, "Look, I'm at the station and the police look at me and ask me some horrible question." Like my brother, I always pick them up from the station, I don't want them to walk around to come home, because they always tell me, "Look, as soon as I get off from the tram the police will ask me like, where are you coming from? Um, why in the middle of the night," while for no reason, "What's your name? Where's your ID?” while they didn't even do anything. So, therefore, we try to pick them up... (Mother 6)

The importance of community involvement and support to parenting was acknowledged by multiple mothers.

We are trying to find different forums where we need to sit together and encourage one another as a community, talk to the children, 'cause sometimes what happens is you talk to a child, you feel like he's not listening or she's not listening to you. So maybe another community member, an elder, a parent, or whatever may talk to him in a different way. And they may get that information better than you as the parents. (Mother 2) 
We talk as a community and we're talking together. We don't want crime. We don't want our family to go to jail and what and caught, and this and this, a lot of things, but we don't want this. (Mother 4)

Some community-based interventions described were organised through pre-existing community networks or churches, while others developed collectively in response to government-funded initiatives. Many were oriented towards reconnecting young people with the South Sudanese community and engaging them in activities such as church groups or sports that were seen to nurture and reinforce positive cultural and social bonds. Others involved parents and elders policing the behaviour of young people from their communities in public in order to reduce their risk of coming into contact with the law (Laskie 2017).

It is beyond the scope of this article to detail these interventions but we highlight them to encourage future consideration of the important and complex relationships between maternal efficacy and community efficacy in intercultural and non-Western parenting contexts, specifically their potentially protective effects against criminality and deviance amplification. In this case, these collective efforts seemingly supplemented mothers' efforts to supervise and support their children and there was a clear attempt by the wider community to promote positive representations of South Sudanese culture and identity to combat the stigma. In this regard, young focus group participants described the community as an important source of support and belonging during the racialised law and order crisis, when their identity as Australians was publicly scrutinised. As one young woman explained: 
What makes me feel like I belong, part of the community is my South Sudanese community. And the way we respond to these negative things that are always thrown at us ... I feel like [a youth club] especially, and the way we, handled the whole situation. How we, we as young African women, especially, we saw a problem within our community and we tried to resolve the issue ... and a lot of people within our community, especially elderlies ... they're straight up with us. They see that we're trying to make a change and we're trying to actually contribute to this white Australia. (Young person 1, Focus Group 2; also quoted in Omitted)

Anecdotally, this illustrates how community-led interventions may supplement parental support by mitigating the consequences of indiscriminate labelling for stigmatised young people. This is seemingly consistent with research that suggests that the protective effects of authoritative parenting styles are enhanced in communities characterised by high collective efficacy (Simons et al. 2005). It further highlights the potential significance of positive community ethnic self-identification (Simmons et al. 2002) when it comes to challenging the depressive effects of stigmatisation.

\section{Conclusion}

This article provides novel theoretical insight into a previously under-researched dimension of how parenting, and more specifically mothering, interacts with labelling and stigmatising processes. It suggests that parenting is not only a potential source of indirect labelling (Matsueda 1992), but also that parenting practices and parental perceptions of children are influenced by societal labelling processes. This may occur in a variety of ways. For example, parents may experience stigma and increased anxiety as a consequence of perceived deviant behaviour, regardless of children's actual involvement in delinquent activities. For women in 
particular, this may contribute to a diminished sense of maternal efficacy in cases where mothers feel disempowered in their ability to help their children navigate the structural and systemic obstacles they face. This is particularly important in post-settlement contexts where mothers and children often face significant intercultural, educational and social challenges, all of which are amplified by racialised law and order rhetoric.

The research further illustrates how stigma, anxiety, and a diminished sense of maternal efficacy may individually or collectively give rise to authoritative modes of mothering and increased familial and community involvement with parenting. In this case, mothers attempted to simultaneously increase supervision and support for their children and these efforts were supported by local community networks. The wider literature on parenting indicates that responses of this nature may be beneficial in terms of reducing young people's involvement in offending. However, it is important to acknowledge that mothers in our study adopted these approaches based primarily on concerns about the safety of their children, and the risks they faced in a hostile social climate, rather than their past or current rule breaking or criminal behaviour. This distinction is important because indiscriminately increasing authoritative parenting practices may inadvertently exacerbate the stigma and strain experienced by young people if it increases perceptions of scrutiny and limits their ability to fully participate in society. The research therefore highlights some complex ways in which labelling processes directly and indirectly interact with parenting and the potential for these interactions to exacerbate pre-existing intercultural and intergenerational tensions in the postsettlement context. Our concern is therefore that inappropriate albeit well-intentioned parental responses triggered by a law and order climate and racialised narratives about youth criminality could serve to increase and extend the effects of labelling and deviance amplification for young people in marginalised communities. However, deviance 
amplification is not inevitable and increasing awareness of this possibility amongst parents and young people from affected communities may enhance their ability to reflexively mitigate this risk. One potential model for collectively negotiating heightened intercultural and intergenerational tensions during a law and order crisis centres on community-led interventions developed to enhance parental supervision and support, strengthen cultural and social bonds, and promote positive community ethnic identification.

\section{References}

Abur, W. (2017). Challenges of Unemployment and Benefits of Employment for South Sudanese People from Refugee Backgrounds in Melbourne, Australia, International Journal of Contemporary Applied Sciences, 4(4), 1-36.

Adams, M., Johnson, J., and Evans, T. (1998) ‘Racial differences in informal labeling effects.’ Deviant Behavior, 19(2) 151-171.

Ali, M. A. (2008). Loss of Parenting Self-Efficacy among Immigrant Parents. Contemporary Issues in Early Childhood, 9(2), 148-160.

Ardelt, M., \& Eccles, J. S. (2001). Effects on Mothers' Parental Efficacy Beliefs and Promotive Parenting Strategies on Inner-City Youth. Journal of Family Studies, 22(8), 944972.

Baak, M. (2018). 'Racism and Othering for South Sudanese heritage students in Australian schools: is inclusion possible?' International Journal of Inclusive Education, 23(2): 125-141. 
Baumrind, D. (1991) 'The influence of Parenting Style on Adolescent Competence and Substance Use.', The Journal of Early Adolescence, 11(1): 56-95.

Becker, H. (1963) Outsiders. New York: The Free Press.

Bernburg, J. and Krohn, M. (2003) 'Labeling, life chances, and adult crime: The direct and indirect effects of official intervention in adolescence on crime in early adulthood.' Criminology, 41(4): 1287-1318.

Bowling, B., \& Westenra, S. (2018). 'A really hostile environment': Adiaphorization, global policing and the crimmigration control system. Theoretical Criminology, 24(2): 163-183.

Brody, G., Conger, R., Gibbons, F., Ge, X., Murry, V., Gerrard, M., and Simons, R. (2001) 'The influence of neighborhood disadvantage, collective socialization, and parenting on African American children's affiliation with deviant peers.' Child Development, 72(4): 12311246.

Browning, C. R., Burrington, L. A., Leventhal, T., \& Brooks-Gun, J. (2008). Neighborhood Structural Inequality, Collective Efficacy, and Sexual Risk Behaviour among Urban Youth. Journal of Health and Social Behaviour, 49, 269-285.

Coleman, P. K., \& Karraker, K. H. (1997). Self-Efficacy and Parenting Quality: Findings and Future Applications. Development Review, 47-85. 
Coleman, P. and Karracker, K. (2003) 'Maternal self-efficacy beliefs, competence in parenting, and toddlers' behavior and developmental status.' Infant Mental Health Journal, 24(2): 126-148.

Condry, R. (2007) Families Shamed: The Consequences of Crime for Relatives of Serious Offenders. Cullompton: Willan.

Cook, E. (2020) 'Motherhood, moral authority and the charismatic matriarch in the aftermath of lethal violence.' Criminology \& Criminal Justice, Online First. DOI: 10.1177/1748895820914359

Deng, S. A. (2016). Fitting the Jigsaw: South Sudanese Family Dynamics and Parenting Practices in Australia (PhD, Victoria University). Retrieved from http://www.vu.edu.au/research

Deng, S. A., \& Marlowe, J. M. (2013). Refugee Resettlement and Parenting in a Different Context. Journal of Immigrant \& Refugee Studies, 11(4), 416-430.

El-Gack, N, \& Yak, G. (2016, September 19). ‘A degree doesn’t count for South Sudanese job seekers.' The Conversation. Viewed on October 4, 2019. Retrieved from: https://theconversation.com/a-degree-doesnt-count-for-south-sudanese-job-seekers-64667

Farrington, D., Piquero, A., and Jennings, W. (2013) Offending from Childhood to Late Middle Age: Recent Results from the Cambridge Study in Delinquent Development. New York: Springer. 
Fozdar, F., \& Torezani, S. (2008). Discrimination and Well-Being: Perceptions of Refugees in Western Australia. International Migration Review, 42(1), 30-63.

Gaffey, J. (2019). 'Melbourne’s ‘African Gangs’ and Media Narratives.' Salus Journal, 7(2), $68-84$.

Glenn, E. (1994) 'Social Constructions of Mothering: A Thematic Overview.' In Glenn, E., Chang, G., and Forcey, L. (Eds.) Mothering: Ideology, Experience and Agency. London: Routledge. Pp. 1-31.

Goffman. E. (1963). Stigma: Notes on the management of a spoiled identity. Englewood Cliffs NJ: Prentice Hall.

Gottfredson, M., \& Hirschi, T. (1990). A General Theory of Crime. California: Stanford University Press.

Hagan, J. (1989) Structural Criminology. New Brunswick: Rutgers University Press.

Hatoss, A., \& Huijser, H. (2010). Gendered barriers to educational opportunities: resettlement of Sudanese refugees in Australia. Gender and Education, 22(2), 147-160.

Hayes, A. (2013) Threatened Identities: The Mothering Experiences of Asylum-Seeking and Refugee Women in England. PhD Thesis. University of East Anglia. Available from: https://ueaeprints.uea.ac.uk/id/eprint/47076/1/2013HaynesAEPhD.pdf (Accessed 11 November 2020) 
Jaysane-Darr, A. (2013). 'Nurturing Sudanese, producing Americans: refugee parents and personhood.’ in Faircloth, C., Hoffman, D.M., \& Layne, L. (Eds) Parenting in Global Perspective: Negotiating Ideologies of Kinship, Self and Politics. London: Routledge, pp. 119-134.

Laskie, A. (2017 11 March) 'South Sudanese community leaders to patrol Moomba in effort to quell trouble.’ The Age. Retrieved from:

https://www.theage.com.au/national/victoria/south-sudanese-community-leaders-to-patrolmoomba-in-effort-to-quell-trouble-20170311-guvyvj.html

Roberts, D. (1995) ‘Motherhood and Crime’. Social Text, 42(Spring): 99-123.

Lawson, E. (2018) 'Bereaved Black Mothers and Maternal Activism in the Racial State.' Feminist Studies, 44(3): 713-735.

Lemert, E. (1967) Human Deviance, Social Problems and Social Control. Englewood Cliffs: Prentice Hall.

Levi, M. (2014). Mothering in transition: The experiences of Sudanese refugee women raising teenagers in Australia. Transcultural Psychiatry, 51(4), 479-498.

Link, B. (1982) ' Mental patient status, work, and income: An examination of the effects of a psychiatric label.’ American Sociological Review, 47(2): 202-215. 
Losoncz, I. (2011). Blocked opportunity and threatened identity: Understanding experiences of disrespect in South Sudanese Australians. Australasian Review of African Studies, 32(2), 118.

Losoncz, I. (2015). “The Government Just Stops Parents Parenting” - Finding Better Ways to Build Safety Around Children in Families from a Refugee Background (SSRN Scholarly Paper No. ID 2601178). Retrieved from Social Science Research Network website: https://papers.ssrn.com/abstract $=2601178$

Losoncz, I. (2017). Goals without Means: A Mertonian Critique of Australia’s Resettlement Policy for South Sudanese Refugees. Journal of Refugee Studies, 30(1), 47-70. https://doi.org/10.1093/jrs/fev017

Macaulay, L. (2020) ‘Australian Sudanese and South Sudanese Youths’ Perspectives on the Youth/Parent Relationship and Its Influence on the Transition to Adulthood'. YOUNG. Online First. doi: 10.1177/1103308820937540

Macaulay, L. and Deppeler, J. (2020) 'Perspectives on Negative Media Representations of Sudanese and South Sudanese Youths in Australia.' Journal of Intercultural Studies, 41(2): 213-230.

Majavu, M. (2020). The ‘African gangs’ narrative: associating Blackness with criminality and other anti-Black racist tropes in Australia, African and Black. Diaspora 13(1): 27-39.

Mamer, D. (2020) Being a Girl in Jieng Society. Juba: Africa World Books. 
Marlowe, J. (2017). Belonging and Transnational Refugee Settlement: Unsettling the Everyday and the Extraordinary. Routledge.

Matsueda, R. (1992) 'Reflected Appraisals, Parental Labeling, and Delinquency: Specifying a Symbolic Interactionist Theory.’ American Journal of Sociology, 97(6): 1577-1611.

Matthews, J. (2008) ‘Schooling and settlement: refugee education in Australia.’ International Studies in Sociology of Education, 18(1): 31-45.

McAra, L. and McVie, S. (2007) 'Youth Justice? The Impact of System Contact on Patterns of Desistance from Offending.’ European Journal of Criminology, 4(3): 315-345.

Renzaho, A. M. N., Green, J., Mellor, D., \& Swinburn, B. (2011). Parenting, family functioning and lifestyle in a new culture: the case of African migrants in Melbourne, Victoria, Australia. Child \& Family Social Work, 16(2), 228-240.

Rusch, N., Angermeyer, M. and Corrigan, P. (2005) 'Mental illness stigma: Concepts, consequences, and initiatives to reduce stigma.' European Psychiatry, 20, 529-539.

Sajjad, T. (2018) 'What’s in a name? 'Refugees', 'migrants' and the politics of labelling' Race \& Class, 60(2): 40-62. 
Salami, B., Hirani, S. A. A., Meherali, S., Amodu, O., \& Chambers, T. (2017). Parenting Practices of African Immigrants in Destination Countries: A Qualitative Research Synthesis. Journal of Pediatric Nursing, 36, 20-30.

Sampson, R. (1986) 'Effects of Socioeconomic Context on Official Reaction to Juvenile Delinquency." American Sociological Review, 51, 876-85.

Sampson, R. and Laub, J. (1993) Crime in the Making: Pathways and Turning Points through Life. Cambridge: Harvard University Press.

Sampson, R. and Laub, J. (1997) 'A Life-Course Theory of Cumulative Disadvantage and the Stability of Delinquency.' in Thornberry, T. (Ed.) Developmental Theories of Crime and Delinquency. New Brunswick: Transaction Publishers, 133-161.

Seccombe, K., James, D., \& Walters, K. (1998) “They think you Ain’t Much of Nothing’: The Social Construction of the Welfare Mother. Journal of Marriage and Family, 60(4): 849865.

Scanlon Foundation. (2016). 'Social cohesion begins at a community level: New paper encourages collaboration’. Viewed 10th October 2019. Retrieved from: http:// scanlonfoundation.org.au/19-september-2016-media-release-discussionpapercommunity

Shephard, S., Newton, D., and Farquharson, K. (2017) 'Pathways to offending for young Sudanese Australian.’ Australian \& New Zealand Journal of Criminology, 51(4): 481-501. 
Shephard, S. and Spivak, B. (2020) 'Estimating the extent and nature of offending by Sudanese-born individuals in Victoria' Australian and New Zealand Journal of Criminology, 53(3): 352-368.

Simons, R., Murry, V., McLoyd, V., Lin, K., Cutrona, C., and Conger, R. (2002)

'Discrimination, crime, ethnic identity, and parenting as correlates of depressive symptoms among African American children: A multilevel analysis.’ Development and Psychopathology, 14(2): 371-393.

Simons, R., Simons, L., Burt, C., Brody, G., and Cutrona, C. (2005) ‘Collective efficacy, authoritative parenting and delinquency: A longitudinal test of a model integrating community-and family-level processes.' Criminology, 43(4): 989-1029.

Smith, E. (2017). The Role of Parental Self-Efficacy, Hardiness, Parenting Stress in Predicting Parental Behaviours. PhD Thesis. Viewed 14th May 2020. Retrieved from https://aquila.usm.edu/dissertations/1452/

Tsai, L., Barr, J., \& Welch, A. (2017) Single mothering as experienced by Burundian refugees in Australia: a qualitative inquiry. BMC Nursing, https://doi.org/10.1186/s12912$\underline{017-0260-0}$

Walsh, J. (2018). 'Report and deport: Public vigilance and migration policing in Australia.' Theoretical Criminology, 24(2): 276-295.

Weber, L. (2013). Policing Non-Citizens. London: Routledge. 
Weber, L, Bowling, B (2009) 'Valiant beggars and global vagabonds: Select, eject, immobilize.’ Theoretical Criminology, 12(3): 355-375.

Weber, L. (2019) “'My Kids Won’t Grow up Here’: Policing, Bordering and Belonging.’ Theoretical Criminology, 24(1): 71-89.

Welch, M. (2012) 'The Sonics of Crimmigration in Australia: Wall of Noise and Quiet Manoeuvring.’ The British Journal of Criminology, 52(2): 324-344.

Windle, J. (2008) 'The racialisation of African youth in Australia.' Social Identities, 14(5): 553-566.

Wright, J. P., \& Cullen, F. T. (2001). Parental Efficacy and Delinquent Behaviour: Do Control and Support Matter? Criminology, 39(3), 677-705.

\section{Funding information:}

The study was supported by an internal grant from XXXX and in-kind support from the XXXX.

\section{Acknowledgements:}

We are grateful to XXXX and the reviewers for their helpful feedback and suggestions. 


\section{University Library}

\section{- M M I N E R VA A gateway to Melbourne's research publications}

Minerva Access is the Institutional Repository of The University of Melbourne

Author/s:

Maher, S;Blaustein, J;Benier, K;Chitambo, J;Johns, D

Title:

Mothering after Moomba: Labelling, secondary stigma and maternal efficacy in the postsettlement context

Date:

2020-12-23

\section{Citation:}

Maher, S., Blaustein, J., Benier, K., Chitambo, J. \& Johns, D. (2020). Mothering after Moomba: Labelling, secondary stigma and maternal efficacy in the post-settlement context. Theoretical Criminology, 26 (2), https://doi.org/10.1177/1362480620981639.

Persistent Link:

http://hdl.handle.net/11343/262689 